\title{
Alimentação em machos e fêmeas do pirá-brasília, Simpsonichthys boitonei Carvalho (Cyprinodontiformes, Rivulidae)
}

\author{
Oscar Akio Shibatta ${ }^{1}$ \\ Antônio José Andrade Rocha ${ }^{2}$
}

\begin{abstract}
Feeding in males and females of pirá-brasília, Simpsonichthys boitonei Carvalho (Cyprinodontiformes, Rivulidae). Simpsonichthys boitonei Carvalho, 1959 has an evident sexual dimorphism, easily observed in the color pattern and body proportions. In order to know the differences in the diet between males and females, the stomach contents of 28 individuals was examined. The Sorensen's index of similarity showed $90.9 \%$ of food items in common between sex. The main food in this species is Cladocera as evidenced in terms of average number, abundance and frequency of occurrence. The presence of vegetable is evidence of a high flexibility of this species in relation to the feeding behavior. Maybe the differences in the social behavior between sex are important in the total amount of ingested food.

KEY WORDS. Simpsonichthys boitonei, diet, anual fish, Distrito Federal, Brasil
\end{abstract}

Simpsonichthys boitonei Carvalho, 1959 vive em brejos temporários do Distrito Federal. Estes ambientes permanecem cheios de água durante poucos meses (e.g. de março a setembro) e, dentro deste período, o ciclo de vida da espécie se completa. O macho territorialista faz uma elaborada apresentação e exibe o seu colorido à fêmea que se aproxima. Após um complexo ritual reprodutivo, ambos se enterram no substrato para a postura e fecundação dos ovócitos (PETERS \& SEEGERS 1978; KADLEC 1986). Na fase seca do brejo os adultos morrem e os ovos permanecem latentes até o retorno das águas. Por estas características, a espécie pode ser classificada como anual (sensu MYERS 1952).

O dimorfismo sexual é uma característica conspícua nesta espécie. O macho é maior e possui coloração avermelhada, com diversas pintas azuis iridescentes sobre o corpo e nadadeiras. A fêmea é castanha com nadadeiras hialinas. As proporções corporais também diferem, sendo maiores os comprimentos das bases das nadadeiras dorsal e anal dos machos (SHIBATTA \& GARAVELLO 1992).

Devido ao ciclo de vida curto, peixes anuais necessitam de um rápido desenvolvimento somático. Certamente, o alimento é um dos recursos importantes relacionados ao desenvolvimento. Em decorrência das diferenças morfológicas ligadas ao sexo e dos padrões comportamentais, este estudo procurou contrastar a alimentação entre machos e fêmeas para levantar possíveis diferenças neste caráter.

1) Departamento de Biologia Animal e Vegetal, Universidade Estadual de Londrina. 86051-970 Londrina, Paraná, Brasil.

2) Curso de Mestrado em Planejamento e Gestão Ambiental, Universidade Católica de Brasilia. SGAN 916, Módulo B, Asa Norte, 70790-160 Brasília, Distrito Federal, Brasil. 


\section{MATERIAL E MÉTODOS}

Para a identificação da espécie utilizamos o trabalho original de descrição feito por CARVALHO (1959). Os exemplares foram coletados no "brejo da cerca", localizado à beira do ribeirão Taquara, um afluente do ribeirão do Gama, Reserva

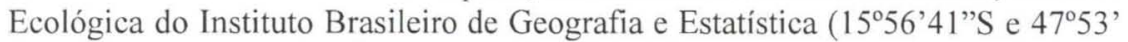
07'W). O mapa da localização geográfica deste ponto pode ser encontrado em ShiBATTA \& GARAVEllo (1992). O habitat desta espécie é o de brejo intermitente, água ácida (pH variando de 4,5 a 5,31, média de 5,03, n =4) e substrato constituído principalmente por turfa.

Três coletas foram realizadas, 3.VII.1987, 10.III.1988 e 27.IV.1988, de 09:00 às 10:00 h. Como aparato de captura foram utilizadas peneiras grandes para arroz. Os peixes capturados foram imediatamente fixados em formol $10 \%$ e levados para o laboratório de Ecologia da Universidade de Brasília (UnB). Após a tomada de dados biométricos (comprimento padrão e peso total), os peixes foram eviscerados e o estômago e intestino foram medidos juntos. Como a maioria dos estômagos não estava repleta, o conteúdo do intestino de todos os exemplares também foi analisado. Os itens foram identificados até o nível taxonômico mais restrito possível e quantificados. Para a identificação das algas utilizou-se as chaves de Bicudo \& BICUDO (1970).

Os estômagos foram analisados quanto a freqüência de ocorrência e a abundância (porcentagem do número de organismos encontrados no total) dos itens ingeridos. Dos percentuais dos números de ocorrências e abundâncias foram calculadas as médias, desvios padrão e o teste $t$ de Student foi usado para a comparação das médias entre os sexos. Também foi realizada a análise de similaridade de Sorensen entre os sexos, utilizando-se apenas o número de itens alimentares.

\section{RESULTADOS E DISCUSSÃO}

Um total de 28 exemplares, 12 machos e 16 fềmeas, foram analisados. $\mathrm{Na}$ primeira coleta foram capturados 10 exemplares, na segunda 11 e na última sete, sendo que em cada coleta foram capturados quatro machos. O comprimento padrão e o peso dos machos variaram respectivamente entre 22,0 a $40,0 \mathrm{~mm}$ e 0,13 a 0,75 $\mathrm{g}$, enquanto as fêmeas apresentaram 18,7 a $32,1 \mathrm{~mm}$ e 0,19 a $0,52 \mathrm{~g}$. Todos os exemplares capturados eram adultos.

O aparelho digestório de ambos os sexos é constituído por uma boca superior protrátil, com dentes cônicos. Um esôfago curto separa a cavidade oral da estomacal. $\mathrm{O}$ estômago é grande e o intestino curto. $\mathrm{O}$ aparelho gastro-intestinal apresentou um comprimento médio de $31,4 \%$ do comprimento padrão em machos e $29 \%$ em fêmeas. Segundo NiKoLSKY (1963), este tipo de aparelho digestório é característico de espécies com hábitos carnívoros.

Qualitativamente a dieta de machos e fêmeas foi muito semelhante. Apenas algas do gênero Micrasterias Agardh, 1827 ex Ralfs e Tetmemorus Ralfs, 1844 não ocorreram em fêmeas e Staurastrum Meyen, 1829 ex Ralfs em machos (Tab. I). O índice de similaridade de Sorensen mostrou que existem $90,9 \%$ de itens comuns entre os dois sexos. 
Tabela I. Somatório, média e desvio padrão dos itens alimentares em machos $(n=12)$ e fêmeas $(n=16)$ de Simpsonichthys boitonei. (p) probabilidade associada ao teste $t$ de Student, (S) desvio padrão da média.

\begin{tabular}{|c|c|c|c|c|c|c|c|}
\hline \multirow{2}{*}{ Itens alimentares } & \multicolumn{3}{|c|}{ Machos } & \multicolumn{3}{|c|}{ Fêmeas } & \multirow{2}{*}{$p$} \\
\hline & Somatório & Média & s & Somatório & Média & S & \\
\hline Acari & 21 & 1,75 & 3,60 & 12 & 0,75 & 1,06 & 0,3685 \\
\hline Algas filamentosas (quatro gèneros) & - & - & - & - & - & - & - \\
\hline Cladocera & 90 & 7,50 & 5,99 & 293 & 18,31 & 17,21 & 0,0000 \\
\hline Closterium & 14 & 1,17 & 2,37 & 47 & 2,94 & 4,19 & 0,1692 \\
\hline Copepoda & 58 & 4,83 & 3,24 & 311 & 19,44 & 31,90 & 0,0884 \\
\hline Diatomacea & 1 & 0,08 & 0,29 & 7 & 0,44 & 0,89 & 0,1533 \\
\hline Diptera (adulto) & 1 & 0,08 & 0,29 & 1 & 0,06 & 0,25 & 0,8433 \\
\hline Escamas & 6 & 0,50 & 0,90 & 3 & 0,19 & 0,40 & 0,2826 \\
\hline Euastrum & 2 & 0,17 & 0,58 & 5 & 0,31 & 1,01 & 0,6351 \\
\hline Micraterias & 2 & 0,17 & 0,39 & 0 & 0,00 & 0,00 & - \\
\hline Nematoda & 8 & 0,67 & 1,23 & 7 & 0,44 & 0,81 & 0,5826 \\
\hline Odonata & 2 & 0,17 & 0,39 & 6 & 0,38 & 0,62 & 0,2863 \\
\hline Chironomidae & 44 & 3,67 & 2,99 & 93 & 5,81 & 4,64 & 0,1500 \\
\hline Restos (material parcialmente digerido) & - & - & - & - & - & - & - \\
\hline Rotifera & 26 & 2,17 & 2,76 & 61 & 3,81 & 4,00 & 0,2792 \\
\hline Sementes & 1 & 0,08 & 0,29 & 1 & 0,06 & 0,25 & 0,8433 \\
\hline Staurastrum & 0 & 0,00 & 0,00 & 4 & 0,25 & 0,58 & - \\
\hline Tecameba & 2 & 0,17 & 0,39 & 2 & 0,13 & 0,34 & 0,7706 \\
\hline Tetmemorus & 1 & 0,08 & 0,29 & 0 & 0,00 & 0,00 & - \\
\hline Tricoptera & 16 & 1,33 & 0,98 & 24 & 1,50 & 1,93 & 0,7688 \\
\hline
\end{tabular}

(-) Informação não disponivel.

Quanto à riqueza dos organismos ingeridos, foi possível notar que existiu equilíbrio entre itens animais e vegetais, além de tecamebas e algas cianofíceas filamentosas (Tab. I). A diferença esteve na quantidade ingerida, com maior número para os itens de origem animal, onde predominaram cladóceros, copépodos, quironomídeos e rotíferos. Em machos, a somatória das abundâncias relativas desses itens representou $71,7 \%$ do total e em fêmeas, $84,1 \%$, evidenciando uma dieta onívora com predominância de alimentos de origem animal. O hábito onívoro com tendência a carnivoria, foi observado por TAYLOR (1992), em Rivulus marmoratus Poey, 1880, também da família Rivulidae. Nesta espécie, dos 16 itens identificados, 14 eram certamente de origem animal. As duas categorias restantes foram detritos e fragmentos não definidos.

Entretanto, pode-se deduzir que o alimento básico do pirá-brasília foram os cladóceros, com 100\% de freqüência e maior abundância, com grande número ingerido em machos e fêmeas. O teste $t$ aplicado a este número indicou que a média de cladóceros foi estatisticamente diferente entre os sexos, ao contrário dos demais itens alimentares. Mesmo assim, os itens ácaros, nematóide, escamas, tecamebas, Tetmemorus, sementes, Micrasterias e diptero adulto foram ingeridos em maior quantidade pelos machos. As fêmeas consumiram maior quantidade de quironomídeos, copépodos, odonatos, rotíferos, tricópteros, Closterium Nitzsch, 1817 ex Ralfs, Cosmarium Corda, 1834 ex Ralfs, Diatomacea e Euastrum Ehrenberg, 1832 ex Ralfs. (Tab. I).

Quanto à freqüência de ocorrência, o predomínio também permaneceu para estes itens mas ficou evidente que tricópteros, algas filamentosas (espécies não 
identificadas dos gêneros Bambusina Kützing, 1845, Cylindrocapsa Reinsch, 1867, Mougeotia Agardh, 1824 e Spirogyra Link, 1820) e Closterium sp. participaram com alta freqüência na dieta, atingindo valores entre 33,3 a 83,3\% (Tab. II).

Tabela II. Abundância (\%) e freqüência de ocorrência (\%) dos itens alimentares em machos $(n=12)$ e fêmeas $(n=16)$ da espécie Simpsonichthys boitonei.

\begin{tabular}{|c|c|c|c|c|}
\hline \multirow{2}{*}{ Itens alimentares } & \multicolumn{2}{|c|}{ Abundãncia (\%) } & \multicolumn{2}{|c|}{ Freqüência de ocorrência (\%) } \\
\hline & Machos & Fêmeas & Machos & Fêmeas \\
\hline Acari & 6,9 & 1,3 & 37,2 & 41,7 \\
\hline Algas filamentosas (quatro gêneros) & - & - & 68,2 & 41,7 \\
\hline Cladocera & 29,6 & 32,5 & 100,0 & 100,0 \\
\hline Closterium & 4,6 & 5,2 & 56,2 & 33,3 \\
\hline Copepoda & 19,1 & 34,5 & 86,8 & 100,0 \\
\hline Diatomacea & 3,0 & 2,8 & 24,8 & 8,3 \\
\hline Diptera (adulto) & 0,3 & 0,1 & 6,2 & 8,3 \\
\hline Escamas & 2,0 & 0,4 & 33,3 & 18,6 \\
\hline Euastrum & 0,7 & 0,2 & 12,4 & 8,3 \\
\hline Micraterias & 0,7 & 0,0 & 16,7 & 0,0 \\
\hline Nematoda & 2,6 & 0,8 & 31,0 & 33,0 \\
\hline Odonata & 0,7 & 0,7 & 31,0 & 16,7 \\
\hline Chironomidae & 14,5 & 10,3 & 93,0 & 75,0 \\
\hline Restos (material parcialmente digerido) & - & - & 70,0 & 80,0 \\
\hline Rotifera & 8,5 & 6,8 & 80,6 & 58,3 \\
\hline Sementes & 0,3 & 0,1 & 6,2 & 8,3 \\
\hline Staurastrum & 0,0 & 0,8 & 0,0 & 18,6 \\
\hline Tecameba & 0,7 & 0,3 & 12,4 & 16,7 \\
\hline Tetmemorus & 0,3 & 0,0 & 8,3 & 0,0 \\
\hline Tricoptera & 5,3 & 2,7 & 55,8 & 83,3 \\
\hline
\end{tabular}

(-) Informação não disponivel.

Foi possível verificar que ocorreram casos eventuais de lepidofagia tanto em machos quanto em fềmeas. Este comportamento pode estar relacionado com o comportamento agressivo (ataques intra-específicos) o que condiz com a maior percentagem de escamas encontrada em machos (33,3\% contra $18,6 \%$ de ocorrência em fềmeas). SAZIMA (1984) propõe que uma das origens da lepidofagia em peixes pode estar relacionada com o comportamento agressivo intra e interespecífico durante a alimentação ou defesa de território. Essas escamas também poderiam ter sido capturadas diretamente do substrato, o que condiz com o hábito bentófago da espécie, evidenciado pela maioria dos itens alimentares.

A importância do item odonatos, em freqüência de ocorrência, foi comparável ao de escamas, com maior número de machos ingerindo este organismo. Entretanto, a abundância média de odonatos foi pouco maior em fềmeas. Devido ao seu tamanho, este item ocupou uma grande porção do estômago, entre 10 a $90 \%$ e, geralmente apenas um indivíduo foi ingerido.

Nematóides também tiveram uma freqüência de ocorrência de aproximadamente $30 \%$ e, embora semelhante entre os sexos, estiveram presentes em maior quantidade em machos. Apesar de estar sendo computado como item alimentar, a sua real natureza (alimento ou parasito) não foi possivel de ser determinada.

Portanto, S. boitonei, um peixe de curto período de vida, apresentou uma flexibilidade alimentar que lhe permitiu ingerir diversas presas. A dieta de $S$. 
boitonei constituiu-se principalmente por alimentos autóctones mas alguns itens alóctones, tais como dipteros adultos e sementes, puderam ser aproveitados ocasionalmente.

A diferença na quantidade ingerida entre sexos, pareceu estar relacionada com o comportamento social como pode ser verificado nas diferentes proporções de escamas (maior em machos) e de copépodos (maior em fêmeas). Machos possuem atividade social durante todo dia, alimentando-se nos momentos em que não estão defendendo o território ou se exibindo para a fêmea. As fêmeas, por outro lado, percorrem diferentes territórios e possuem menor número de interações sociais conseguindo desta maneira, ingerir mais alimento.

Pode-se concluir que, apesar do marcado dimorfismo sexual em pirá-brasília, existiram semelhanças qualitativas na dieta entre machos e fêmeas, embora o item cladócera possa ser considerado numericamente importante para a distinção dos sexos.

AGRADECIMENTOS. Ȧs Dras Sirlei T. Bennemann e Ângela Teresa Silva-Souza pela leitura do manuscrito e valiosas sugestões. Ao Dr. Mauro Ribeiro, do Instituto Brasileiro de Geografia e Estatística (IBGE) pela permissão de coleta do material. A Maria das Graças Machado de Souza, pelo auxilio nas questões ficológicas. Ao CNPq pela bolsa de estudos concedida ao autor senior. Aos consultores da Revista Brasileira de Zoologia que fizeram excelentes observações a este trabalho.

\section{REFERÊNCIAS BIBLIOGRÁFICAS}

Bicudo, C.E.M. \& R.M.T. Bicudo. 1970. Algas de águas continentais brasileiras: chave ilustrada para identificação de gêneros. São Paulo, Fundação Brasileira para o Desenvolvimento do Ensino de Ciências, 228p.

Carvalho, A.L. 1959. Novo gênero e nova espécie de peixe anual de Brasília, com uma nota sobre os peixes anuais da baixada fluminense, Brasil (Pisces -Cyprinodontiformes - Fundulinae). Bol. Mus. Nac., n.s., Rio de Janeiro, 201: 1-10.

Kadlec, J. 1986. The lyre-finned pearfish: Cynolebias boitonei. Trop. Fish Hobb. 95 (1): 70-73.

Myers, G.S. 1952. Annual fishes. Aquarium Jour. 23: 125-141.

Nikolsky, G.V. 1963. The Ecology of fishes. London, Academic Pres, 352p.

Peters, F. \& L. Seegers. 1978. Ein Fisch ohne Bauchflossen -Cynolebias boitonei. Aquarien Mag. 1218: 390-395.

SAZIMA, I. 1984. Scale-eating in characoids and other fishes, p. 9-23. In: T.M. ZARET (Ed.). Evolutionary ecology of neotropical freshwater fishes. The Hague, W. Junk Publishers, 175p.

Shibatta, O.A. \& J.C. Garavello. 1992. Descrição de uma nova espécie do gênero Cynolebias Steindachner do Brasil Central (Pisces: Cyprinodontiformes). Comun. Mus. Ciêncis PUCRS, sér. zool., Porto Alegre, 5 (11): 179-195.

TAYLOR, D.S. 1992. Diet of the killifish Rivulus marmoratus collected from land crab burrows, with further ecological notes. Env. Biol. Fish. 33: 389-393.

Recebido em 03.1.2000; aceito em 02.V.2001 